the guidelines on the private sector. A bill seeking to do so, and requiring the registration of all industrial activities using recombinant DNA techniques, has been intr duced by Senator Adla Stevenson Jr; but it has so far failed to gain any significant support, either inside Congress or without.

David Dickson

\section{Comecon Science High T, Low K}

A NEW Comecon International Laboratory of High Magnetic Fields and Low Temperatures is to be built in Wroclaw during the next Five Year Plan (1971-1985) by the Academies of Science of Poland, Bulgaria, the Soviet Union and East Germany, with possible participation also by Czechoslovakia. This will replace the existing somewhat cramped premises which have served the laboratory since 1968.

According to $\mathrm{Dr}$ Wlodzimierz Trzebiatowski, until recently the Director of the Laboratory, and who still, in retirement, takes a keen personal interest in it, Wroclaw was originally chosen as the site of the laboratory for a number of practical reasons. First the Polish Academy of Sciences already had a flourishing Institute of Low Temperature and Structure Research in Wroclaw. Wroclaw is near the important East German science centres of Dresden and Berlin, and helium, essential for low temperature work, is available from a Polish extraction plant only $100 \mathrm{~km}$ away. Finally, just as the laboratory was being planned, the Lower Sjleskan electricity board, was installing new generators in the Wroclaw tramway substation and was willing to donate the old generators to the Academy of Science.

The present laboratory is concerned with such things as the properties of hard semiconductors, new magnetic materials and the measurement of specific heats below $1^{\circ} \mathrm{K}$. Cooling below $4.2^{\circ} \mathrm{K}$ is effected by helium cooling in the field of superconducting magnets of $5 \mathrm{~T}$ and $15 \mathrm{~T}$, and work is in progress on adiabatic demagnetization of nuclear and electron paramagnetics, allowing temperatures below $0.1 \mathrm{~K}$ to be attained.

The laboratory has a special interest in compounds of uranium with non-metals of the $\mathrm{Vb}$ and VIb groups - a speciality begun by Professor Trzebiatowski at the Low Temperature Institute of the Academy of Sciences in the early 1950s. (Since his initial discovery of ferromagnetic transition in uranium hydride $\mathrm{UH}_{3}$, some fifty such uranium compounds, mostly chalcogenides, have been discovered there.) One new project, of especial interest to Dr Evgeni Leyarovski, of the Bulgarian Academy of Sciences, who was Deputy Director of the Wroclaw Laboratory from 1974-1977, is the study of superconductors

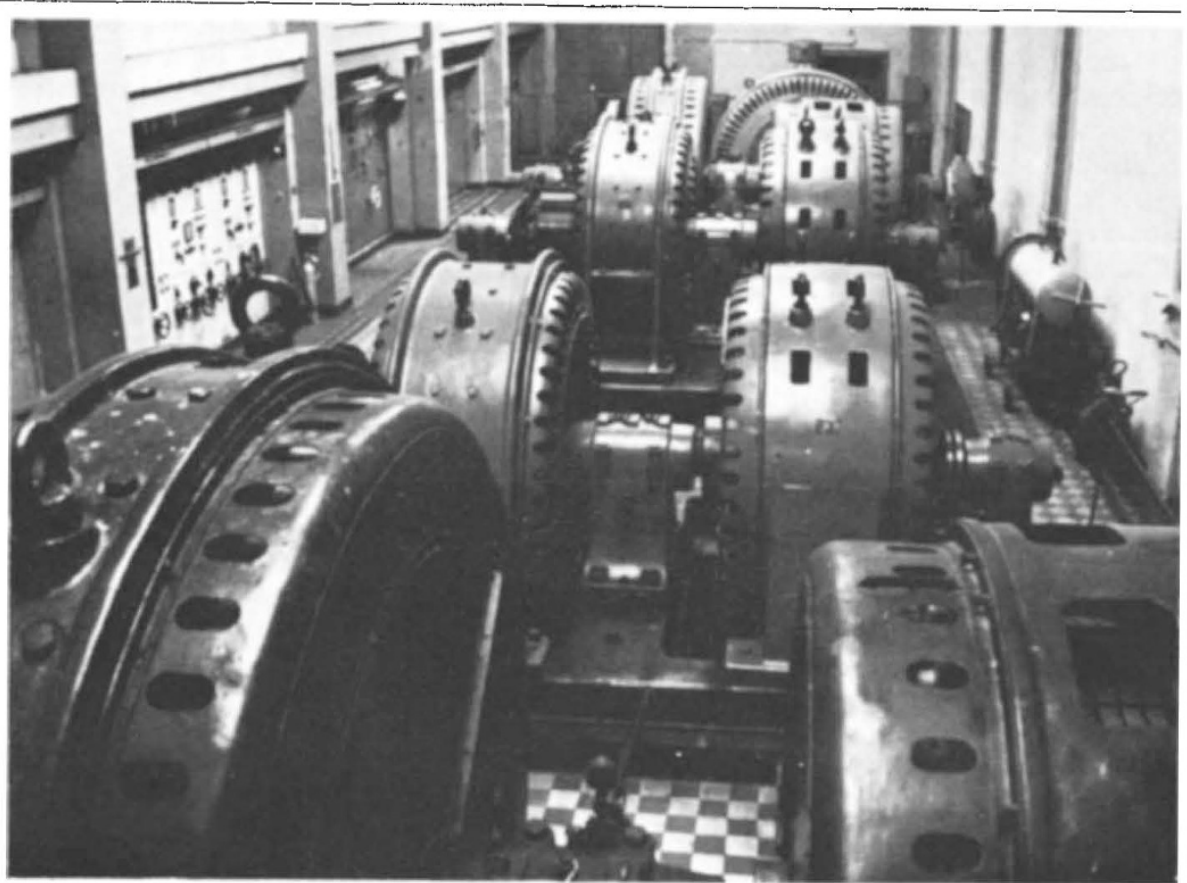

Tramway generators keep turning in Wroclaw

with magnetic impurities. Research on this phenomenon is also going forward in Sofia, but even with their new 5 tesla superconducting magnets installed this spring, the Bulgarians will still have to do much of their work in Wroclaw.

Nevertheless, even Wroclaw cannot at present offer the facilities which an international Comecon laboratory needs. Far more laboratory space is required, and, more important, the ex-tramway generators can operate only one of the three magnets at a time, so that the various teams often have to queue for "magnetic time". The new site, on the banks of the Odra, will provide space and facilities for more magnets with higher fields as well as an ample supply of water for cooling the electromagnets.

Vera Rich

\section{Soviet oil}

\section{No real shortage}

THE Soviet Union has initiated a major change in its method of estimating oil production costs which will result in a dramatic increase in production from proven fields, says a report* published last week by PetroStudies, a Swedish group specialising in the analysis of the Soviet oil and gas industry. The report disagrees sharply with CIA forecasts that the Soviet Union will suffer a shortfall in oil production. The CIA prediction has been used repeatedly in recent months by US oil officials to suggest that a Soviet oil shortage was leading it to have a material

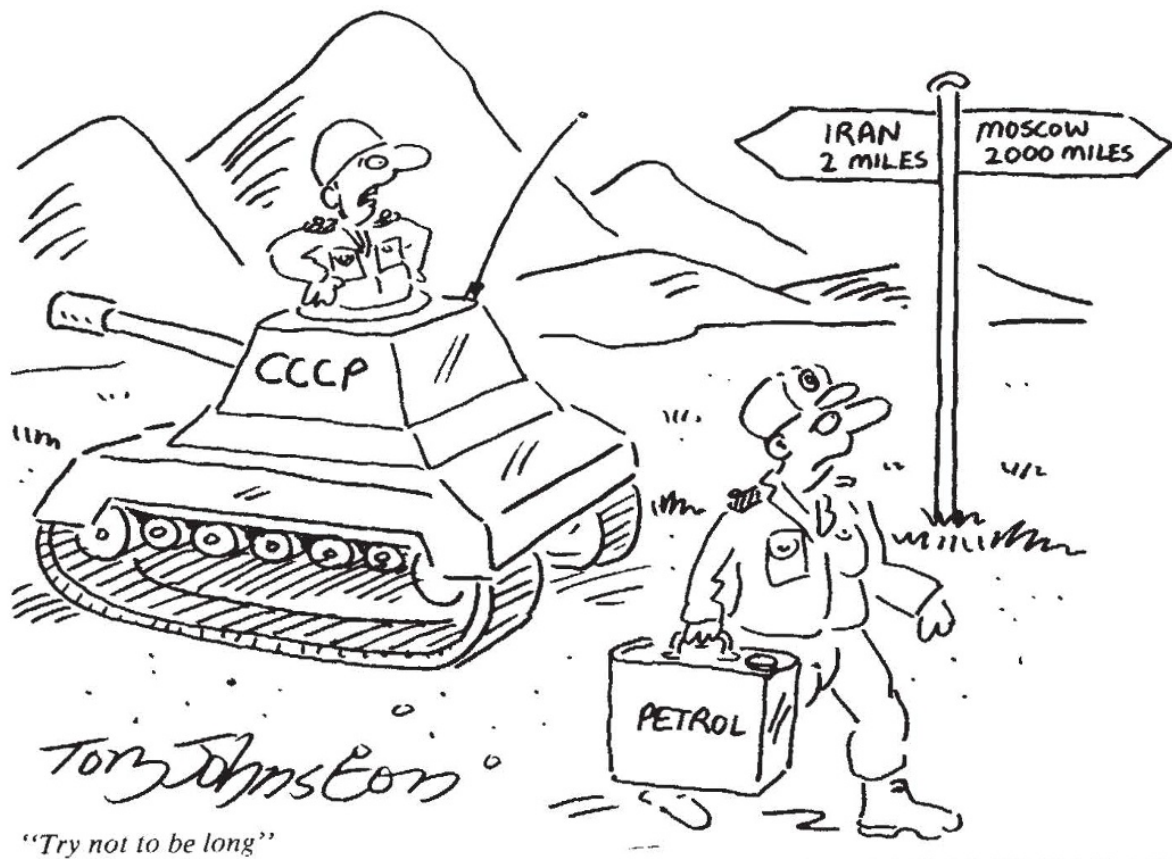


interest in controlling the Middle East.

The PetroStudies group finds that a recent 11-20 fold rise in the reference price of oil, from $\$ 0.75-\$ 1.50$ to $\$ 17-\$ 20$ per barrel, will correct the "systematic underexploitation of Soviet oilfields over the past thirty years'". The reference price is the figure planners use to assess the cost of opening new oil fields, compared with the cost of intensively developing existing ones. The higher reference price represents a recognition by Soviet planners that development of new oil fields has created unacceptable pressures on capital, labour and material, necessitating a new economic approach to oil development. The PetroStudies report says that the new policy means that "there is no danger whatsoever that the USSR will be forced to become a net importer of oil this decade and highly improbable that it will become so in the 1990s"'.

An additional feature of the new policy will be a decline in Soviet imports of American oilfield machinery, the report says. Intensive mining of existing fields by many wells will substitute for high capacity pumping from a few wells, a policy which will significantly decrease Soviet dependence on US-produced high capacity oil pumps.

According to the International Herald Tribune, diplomatic sources have suggested that the PetroStudies' findings may be "part of a Soviet campaign of disinformation',. M Jermol of PetroStudies explained that their analysis is based on original Soviet sources obtained though normal institutional channels. The materials include Russian texts of official oil industry documents, specialised books and journal articles, reports from Soviet research institutes, and petroleum conferences, extending back over ten years. "It would be impossible to base a report like this on a few privileged documents" said Jermol.

Joe Schwarz

*'Soviet oil production reform of 1980 and its potential', PetroStudies Co., Sjoblads vag 27, S-21370 Malmo, Sweden. 260pp.

\section{Instruments}

\section{New homes for old instruments}

Is Britain's scientific heritage being ignored and forgotten by its museums? Arthur Frank, a collector of scientific instruments, believes that it is. About half of his collection of instruments dating from the early eighteenth century, which runs into thousands, has been placed in British museums - mainly central museums in London and Edinburgh. But the other half is on display only in his garage in Jersey, while Mr Frank searches for more conventional homes, so far with little success.

There are more than 1,100 museums in Great Britain and Ireland, but Mr Frank says that fewer than a dozen of them take scientific instruments seriously. But they do appear to differ in their reactions. Some have bought or borrowed instruments from Mr Frank. Others have declined to do so either on the grounds that the instruments which he has available would not fit in well with existing collections or because they would not be able to afford the prices asked. But many, mainly provincial museums, have said that they are the wrong organisation to approach because they do not have the expertise to judge scientific instruments.

One of the few provincial museums to house part of the Frank collection, however, is the Museum and Art Gallery, Doncaster, Yorkshire. Mr J Barwick, the museum's director, had to draw on outside expertise to mount the exhibition. His interest in the Frank collection stemmed from his wish to display a selection of early mining and surveying instruments appropriate to an old mining and engineering town; the public response has now persuaded him also to borrow some of Mr Frank's microscopes and astronomical instruments and he is planning to extend this section of the museum.
Doncaster Museum's special interests may be exceptional. Elsewhere, according to one official, regional and municipal museums are likely to be more interested in a display of instruments representative of different types than of a specialist subcollection from Mr Frank's garage.

Mr Frank, nevertheless, is determined that his instruments should not be disposed of one by one. He also requires that recipients of objects from his collection should catalogue the instruments and put them all on display. He says that he is prepared to make gifts of them, lend them for twenty-one years, or sell them at twothirds of the estimated value, dealing with learned societies as well as museums. One snag that may deter some museums is that Mr Frank's valuations seem high.

So far, the large specialist and national museums have been the chief recipients either loaning the instruments or more usually buying them under the two thirds of value offer. The Science Museum in London has about 1,500 of his cameras and accessories, and there is a permanent exhibition of field and opera glasses and of prismatic binoculars. Inevitably, however, such a museum is primarily concerned to fill gaps in its present collection.

Elsewhere in Britain, the Royal Scottish Museum in Edinburgh has a display showing the development of the achromatic microscope in the formative years 1800-1860 (and is also negotiating for the remaining Scottish instruments in the Frank collection). There is also a collection of astronomical and terrestrial telescopes at the Royal Observatory, Edinburgh.

The parts of the Frank collection not yet disposed of are strong on spectroscopic and stereoscopic devices, as well as early spectacles. He is especially proud of his Marshall microscope (circa 1700) and his Ramsden astronomical instruments from the late 1700 s.

Judy Redfearn

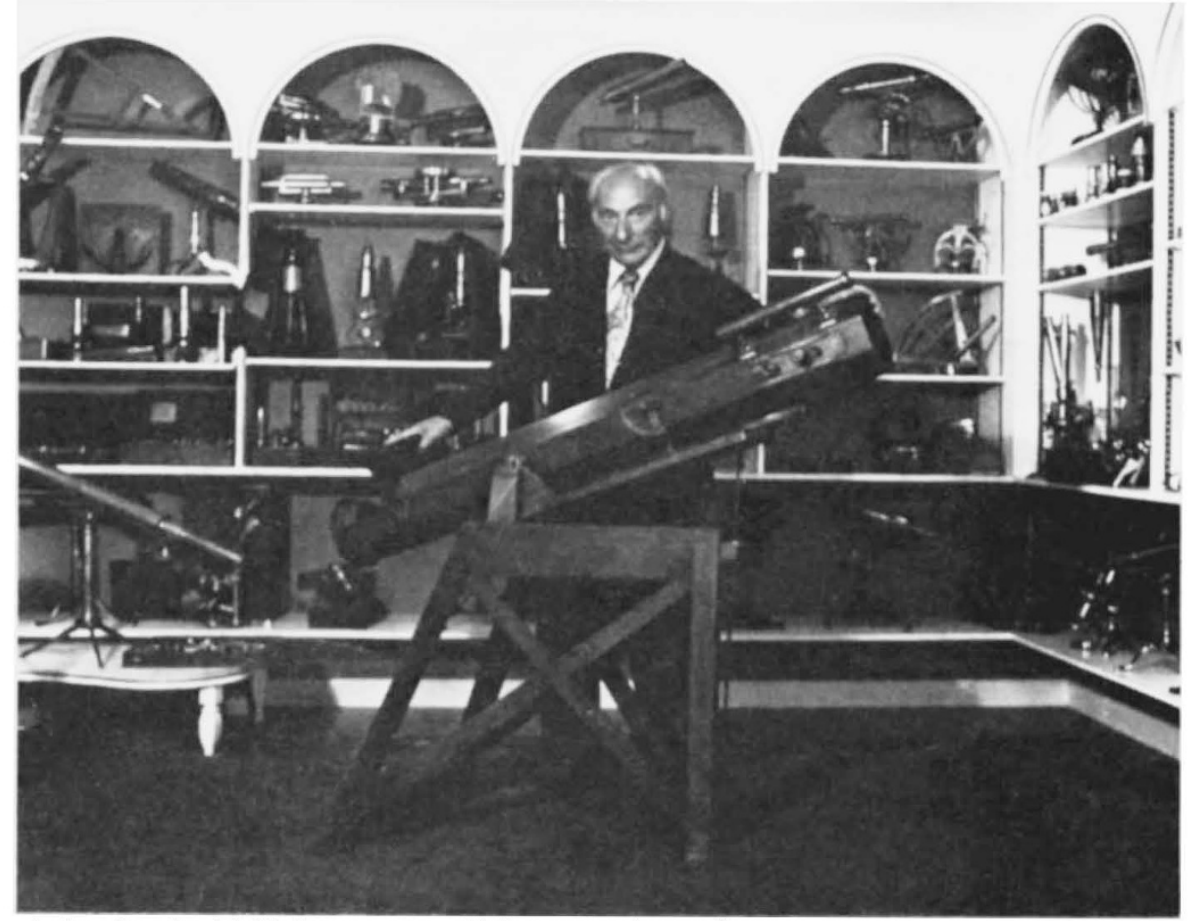

Arthur Frank with his instruments: gift horse or salesman? 